o bulbo ocular, a lente, o bulbo olfatório, a glândula parótida e a medula oblonga. Diante da riqueza de detalhes anatômicos fornecidos pela RM é de extrema importância à pesquisa pelo conhecimento da normalidade, antes de partirmos para a exploração de alterações.

Fonseca Pinto, A C. B. C. ';

Clemente E. A. ${ }^{2}$; Caldas, G. M. M. ${ }^{2}$; Sterman, F. A. ${ }^{3}$; Cortopassi, S. R. G. ${ }^{4}$

\section{4 - Estudo dos aspectos radiográficos observados aos exames simples e contrastados de cães com compressão extra dural}

1- Professora Assistente do Departamento de Cirurgia da Faculdade de Medicina Veterinária e Zootecnia da Universidade de São Paulo, São Paulo-SP

2- Acadêmicos da Faculdade de Medicina Veterinária e Zootecnia da Universidade de São Paulo, São Paulo-SP

3- Professor Associado do Departamento de Cirurgia da Faculdade de Medicina Veterinária e Zootecnia da Universidade de São Paulo, São Paulo-SP

4- Professora Doutora do Departamento de Cirurgia da Faculdade de Medicina Veterinária e Zootecnia da Universidade de São Paulo, São Paulo-SP

A herniação discal é uma das principais afecções da medula espinal. Ela foi classificada por Hansen como: tipo I, que se caracteriza pela degeneração, ruptura do anel fibroso dorsal e extrusão do núcleo pulposo para o canal espinal e acomete mais frequentemente raças condodistróficas, e tipo II que se caracteriza pelo abaulamento do disco intervertebral sem a completa ruptura do anel fibroso (protrusão discal) e que acomete mais freqüentemente raças não condodistróficas. $\mathrm{O}$ presente trabalho teve como objetivo estudar os aspectos radiográficos observados em cães portadores de compressão extra-dural (CED) bem como as raças, idades e regiōes mais freqüentemente acometidas. Para tanto foram avaliadas radiografias simples e contrastadas de 22 cães com CED encaminhados ao serviço de diagnóstico por imagem do Hospital Veterinário da Faculdade de Medicina Veterinária e Zootecnia da Universidade de São Paulo. Os exames simples foram realizados em projeçào látero-lateral e o contrastado em projeções látero-lateral, ventro-dorsal e oblíquas quando necessário. Os aspectos radiográficos estudados ativeram-se somente aos pontos de CED diagnosticados a mielografia. Dos 22 cães estudados, 10 (45\%) foram classificados como portadores de extrusão (Hansen tipo I), $9(41 \%)$ apresentavam associação de extrusão $e$ protrusão (Hansen tipo I e II), em $2(9 \%)$ não foi possivel classificar a CED e em apenas 1 $(5 \%)$ foi diagnosticado somente protrusão (Hansen tipo II). No total foram observados 37 compressões extra-durais. A região mais acometida foi a tóraco-lombar (de T11 a L2) com 17 observações $(46 \%)$. Em 24 das 37 observações $(65 \%)$ foram visibilizadas calcificaçào do disco intervertebral correspondente, em 21 delas $(57 \%)$ diminuição do espaço intervertebral e em $17(46 \%)$ foi possível identificar a opacificação do forâmen intervertebral. A progressão da coluna de contraste foi interrompida em 13 cães $(59 \%)$ impossibilitando a adequada avaliaçào pela mielografia da região caudal ao ponto de obstrução, porém apenas em 2 casos $(9 \%)$ não se conseguiu avaliar e definir o tipo de CED a partir da associação com os achados radiográficos do exame simples. Dos 22 animais estudados, $50 \%$ eram da raça dachshund e as idades variaram de 3 a 11 anos com média de 6 anos. Os resultados obtidos demonstraram que a mielografia foi de grande importância para o diagnóstico e a avaliaçào da CED, e que o exame simples também conferiu informações importantes para o estabelecimento do diagnóstico. Nos casos avaliados, a regiào da coluna mais acometida por lesōes foi a tóraco-lombar e a maior ocorrência foi a herniação discal do tipo I (extrusão). Nos pontos de CED diagnosticados a mielografia foram observadas associaçòes de outros importantes aspectos que complementaram o diagnóstico, como: a calcificaçào do disco intervertebral, a diminuição do espaço intervertebral e a opacificação do forâmen intervertebral. Foi observado também que a raça mais acometida por esse tipo de lesão foram os dachshund e que não houve predisposição etária, mas a média de idade dos animais acometidos foi de 6 anos. 